\title{
Dívida Pública e Estabilidade de Preços no Período Pós-Real: Explorando Relações Empíricas
}

Helder Ferreira de Mendonça
Professor do Departamento de Economia da UFF e Pesquisador do CNPq

\begin{abstract}
RESUMO
O objetivo do artigo é estudar evidências empíricas para a dinâmica da dívida pública a partir de algumas variáveis que estão relacionadas à busca da estabilidade de preços no período posterior à introdução do Plano Real. Para tanto, é feito um modelo auto-regressivo vetorial (VAR) para analisar as regularidades empíricas provenientes da relação entre: necessidades de financiamento do setor público - juros reais $X$ resultado primário do setor público $X$ câmbio $X$ inflação $X$ dívida pública. Os resultados encontrados denotam que a estabilidade de preços obtida no período não é suficiente para promover reduções no estoque da dívida pública e que é necessário uma nova estrutura de indexação.
\end{abstract}

\section{PALAVRAS-CHAVE}

câmbio, inflação, necessidades de financiamento do setor público primário e juros reais, dívida pública

ABSTRACT

The objective of this paper is to study the empirical evidences for the dynamic of the public debt from some variables that are associated with the search for price stability in the period after the introduction of the Real plan. For this, a vector autoregression model is made (VAR) for analyzing the empirical regularities from the relationship among: primary result $X$ public sector borrowing requirements (real interest) $X$ exchange rate $X$ inflation $X$ public debt. The findings denote that the price stability observed in the period is not enough to promote reductions in the public debt and that a new indexation framework is necessary.

KEY WORDS

exchange rate, inflation, public sector borrowing requirements (primary and real interest), public debt

JEL Classification

E62, E63

EST. ECON., SÃO PAULO, V. 34, N. 2, P. 345-368, ABRIL-JUNHO 2004 


\section{INTRODUÇÃO}

O período recente tem sido caracterizado por uma padronização, em diversos países, no que se refere à condução das políticas monetária e fiscal. Quanto à política monetária, o receituário básico consiste na implementação de uma política voltada para a busca da estabilidade de preços e fortalecimento da independência do banco central. No que diz respeito à política fiscal, o ponto central é o esforço que a autoridade política deve realizar para minimizar os custos oriundos do endividamento público.

Um elemento de significativa importância para o sucesso da estrutura supracitada diz respeito à conquista da credibilidade oriunda da condução das políticas fiscal e monetária. A tentativa do uso da política monetária para o aumento da confiança do público na formação das expectativas pode ter êxito apenas no caso de as finanças públicas mostrarem-se equilibradas. Devese ressaltar que a busca da estabilidade de preços, por si só, pode implicar efeitos negativos à economia (elevada taxa de juros ou perda de reservas internacionais) no caso de o mercado não acreditar na solvência da dívida pública. Não obstante, a perda de credibilidade da política monetária implica uma taxa de juros mais elevada capaz de prejudicar o equilíbrio fiscal devido ao aumento das despesas financeiras com o pagamento de juros.

As observaçóes acima representam o centro de uma controvérsia formada por acadêmicos e responsáveis pela condução da política econômica no Brasil em relação aos possíveis efeitos, para o equilíbrio fiscal, decorrente de uma política monetária austera. De um lado, há o argumento de que uma política monetária concentrada no combate à inflação evita a manifestação do viés inflacionário do governo, disciplinando seus gastos, o que, por sua vez, contribui para o alcance do equilíbrio fiscal. Por outro lado, existe a idéia de que o uso de uma elevada taxa de juros como principal instrumento de combate à inflação acarreta um aumento no pagamento de juros reais, contribuindo para uma maior necessidade de financiamento do setor público. ${ }^{1}$ Logo, o efeito de uma política monetária contracionista poderia impli-

1 Para uma análise do efeito de menores déficits orçamentários sobre a taxa real de juros, ver TAYLOR (1995). 
car a necessidade da geração de superávits primários para pagar os custos do acréscimo da dívida enquanto a credibilidade está sendo construída. ${ }^{2}$

O objetivo do artigo é estudar evidências empíricas para a dinâmica da dívida pública a partir de algumas variáveis que estão relacionadas à busca da estabilidade de preços no período posterior à introdução do Plano Real. Para tanto, é feito um modelo auto-regressivo vetorial (VAR) para analisar as regularidades empíricas provenientes da relação necessidades de financiamento do setor público - juros reais $\mathrm{X}$ resultado primário do setor público $\mathrm{X}$ taxa de câmbio X taxa de inflação X estoque da dívida pública. Além desta introdução, o artigo encontra-se dividido em mais quatro seções. A primeira seção apresenta a justificativa para a utilização das séries selecionadas e o porquê da análise em dois subperíodos. A segunda seção apresenta os resultados empíricos para o período compreendido entre agosto de 1994 e dezembro de 1998. A terceira seção analisa as evidências empíricas para o período que se estende de janeiro de 1999 até abril de 2003. Por último, é apresentada a conclusão do artigo.

\section{DADOS E DEFINIÇÃOO DE SUBPERÍODOS}

Além da dívida pública (DIVPUB), as variáveis selecionadas para análise são: necessidades de financiamento do setor público - juros reais, resultado primário do setor público, câmbio, e inflação. A justificativa para o uso dessas variáveis pode ser compreendida da seguinte forma:

i) necessidades de financiamento do setor público - juros reais (NFSPJR): esta variável representa uma importante conexão entre a política monetária e o endividamento público, pois grande parte da dívida pública está indexada à taxa de juros básica da economia (SELIC). Portanto, flutuações na taxa de juros implicam variações significativas sobre essa variável e, por conseguinte, sobre a dívida pública;

(ii) resultado primário do setor público (NFSPP): outra variável que revela uma ligação entre o comportamento da autoridade monetária e o endi-

2 Este fenômeno é denominado por KING (1995) como "desagradável aritmética fiscal". 
vidamento público. No caso de uma condução de política monetária voltada para a busca da estabilidade de preços há um entrave para o financiamento do governo via emissão monetária, o que, por conseqüência, estimula um maior equilíbrio para o resultado primário;

(iii) câmbio: variável-chave para a conquista da estabilidade de preços e sua manutenção até janeiro de 1999. Da mesma forma que no caso da taxa de juros, o câmbio possui papel relevante sobre a dívida pública por ser um dos seus principais indexadores;

(iv) inflação (INF): esta variável denota se o governo está monetizando ou não a dívida pública.

Com base nas informações supracitadas, a equação para a dívida pública pode ser expressa da seguinte forma:

$$
\text { DIVPUB }=f(N F S P J R, \text { NFSPP, CAMBIO, INF })
$$

sendo os sinais esperados das relações expressos pelas derivadas parciais abaixo:

$\partial f / \partial N F S P J R>0 ; \partial f / \partial N F S P P>0 ; \partial f / \partial C A M B>0 ; \partial f / \partial I N F<0$.

Serão realizadas estimações para o período que vai de agosto de 1994 a abril de 2003 utilizando-se dados mensais para o estoque da dívida do setor público (dívida líquida \% PIB), necessidades de financiamento do setor público - juros reais (\% PIB), resultado primário (necessidades de financiamento do setor público \% PIB - primário), câmbio (R\$/US\$ comercial mensal), e inflação (IPCA - variação \% 12 meses).

Ao longo do período que se pretende analisar houve uma mudança significativa na condução da política econômica devido à mudança do regime de câmbio em janeiro de 1999. Com o fím do uso da taxa de câmbio como principal estratégia de combate à inflação houve a necessidade de buscar uma nova âncora nominal. Em junho de 1999 foi implantado um novo regime monetário no Brasil com base na utilização de metas para a inflação. ${ }^{3}$

3 Para uma análise da teoria do regime de metas de inflação e do seu funcionamento no Brasil, ver de MENDONÇA (2001 e 2002) e NETO (1999). 
Nesse novo modelo para a condução da política econômica tornou-se explícito o uso da taxa de juros de curto prazo como principal instrumento para o alcance da meta de inflação anunciada.

Diante da modificação no regime de câmbio torna-se necessário avaliar se a mudança observada altera, de forma significativa, os resultados para a estimação da dívida pública ao longo do período sob análise. Para tanto, é realizado o teste de estabilidade dos parâmetros de Chow para verificar se os coeficientes estimados do modelo são estáveis ao longo da amostra. ${ }^{4}$ Para a realização do teste os dados foram divididos em dois subperíodos (agosto de 1994 a dezembro de 1998 e janeiro de 1999 a abril de 2003), de forma que se for observada uma diferença significativa para as estimações relativas a cada subperíodo, há uma mudança estrutural na relação sob análise. O resultado obtido (vide Tabela 1) mostra que houve uma mudança estrutural. Logo, é indicado fazer a análise do período que se estende de agosto de 1994 a abril de 2003 por meio dos dois subperíodos mencionados.

TABELA 1 - TESTE DE CHOW - ESTABILIDADE DOS PARÂMETROS (1994:8 - 2003:4)

\begin{tabular}{lccr}
\hline \multicolumn{4}{c}{ DIVPUB $=b_{0}+b_{1}$ NFSPJR $+b_{2}$ NFSPP $+b_{3}$ CAMBIO $+b_{4}$ INF $+u$} \\
\hline F-statistic & 42,92669 & Probability & 0,000000 \\
Log likelihood ratio & 124,0588 & Probability & 0,000000 \\
\hline
\end{tabular}

Nota: Subperíodos 1994:8/1998:12, 1999:1/2003:4.

\section{RESULTADOS EMPÍRICOS: AGOSTO DE 1994 - DEZEMBRO DE 1998}

Para que se possa fazer uso de um modelo auto-regressivo vetorial (VAR) é necessário que as séries utilizadas sejam fracamente estacionárias. ${ }^{5}$ Assim,

4 O teste de Chow compara a soma do quadrado dos resíduos obtida pela estimação da equação que abrange toda a amostra com a soma dos quadrados dos resíduos das equações estimadas para cada subperíodo.

5 Em um modelo VAR o valor corrente de uma variável $\mathrm{y}_{\mathrm{t}}$ é explicado por seus próprios valores defasados e por valores defasados da variável $\mathrm{x}$, adicionados a um termo estocástico $\mathrm{e}_{\mathrm{t}}$. De forma análoga, o valor de $\mathrm{x}_{\mathrm{t}}$ é explicado por seus valores defasados, pelos valores defasados de $\mathrm{y}_{\mathrm{t}} \mathrm{e}$ por um termo $\mu_{\mathrm{t}}$. É admitido que o termo estocástico tem média zero, variância constante $\sigma_{\mu}^{2}$ e que não apresenta correlação serial. Portanto, será considerado na análise apenas regularidades e padrões passados de dados históricos como base para previsão. 
uma primeira condição a ser avaliada é verificar se as séries: NFSPJR, NFSPP, CAMBIO, INF, e DIVPUB possuem raiz unitária. Por meio de inspeção gráfica dos correlogramas dos valores originais das séries supracitadas (vide Fgura 1) verifica-se que na maioria das séries os coeficientes de autocorrelação simples declinam de forma lenta e gradual à medida que o número de defasagens aumenta. Logo, constata-se que os valores atuais dependem fortemente dos valores passados, o que indica a existência de raiz unitária.

\section{FIGURA I - EVOLUÇÃO E CORRELOGRAMA DAS SÉRIES}
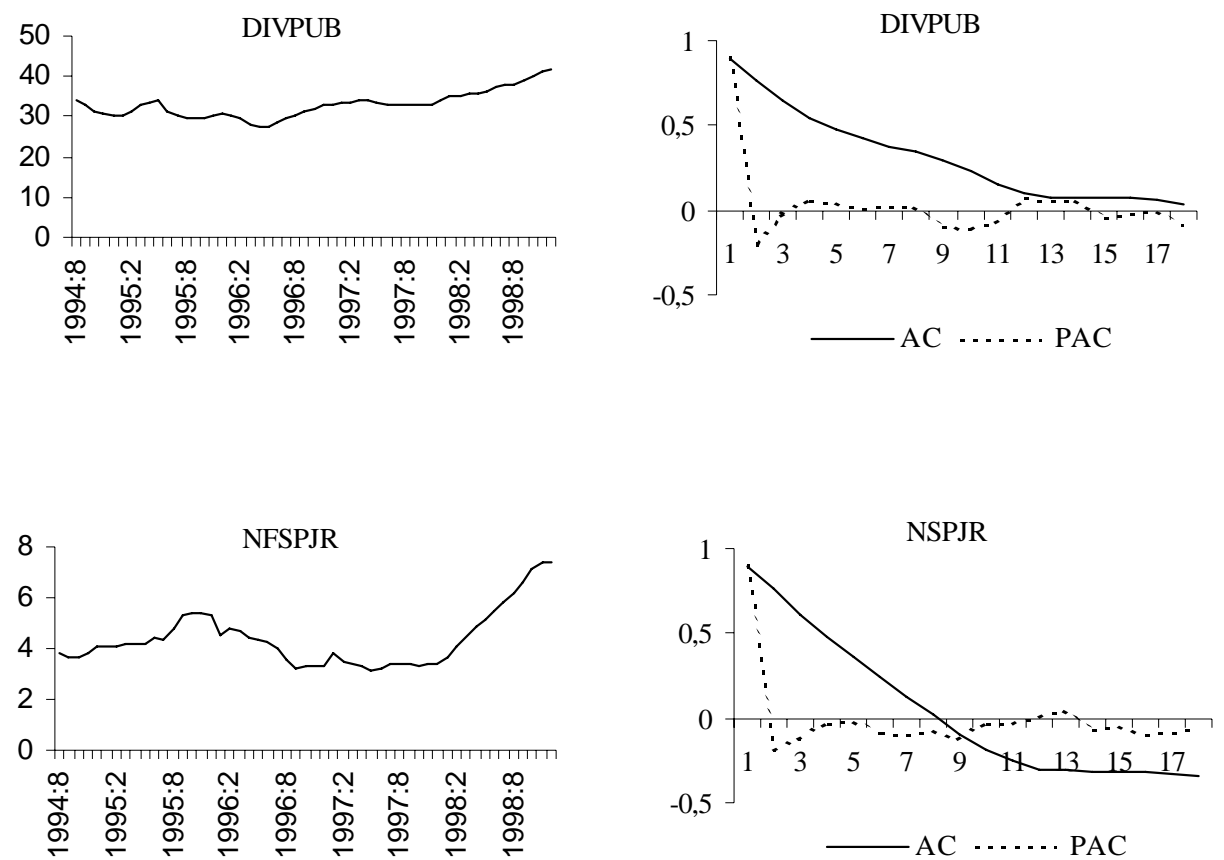

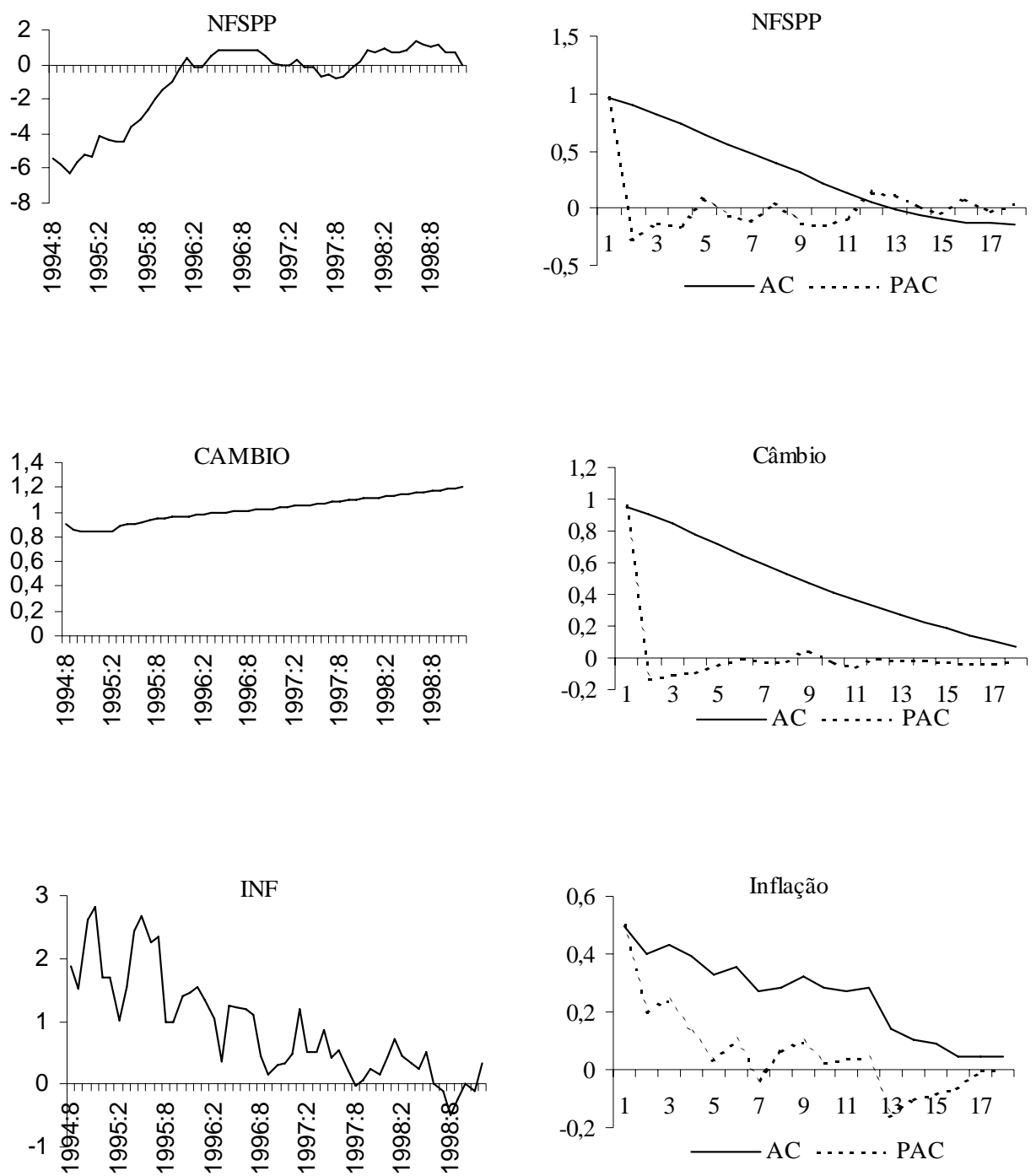

Com o objetivo de testar a existência ou não de raiz unitária das séries foi realizado o teste ampliado de Dickey-Fuller (ADF). O critério para a seleção das defasagens segue o procedimento do geral para o específico, inicia-se com uma defasagem arbitrariamente elevada, que é reduzida de forma gradativa até alcançar a melhor estrutura. (DOLADO, JENKINSON, SOSVI- 
LLA-R OVERA, 1990). O resultado obtido indica a rejeição da hipótese nula para as séries NFSPP e INF, o que revela que as séries são estacionárias em nível, I(0). Por outro lado, há aceitação da hipótese nula (séries não estacionárias) para os valores originais das séries DIVPUB, NFSPJR e Câmbio. Em relação às primeiras diferenças, a hipótese nula é rejeitada para todas as séries ao nível de significância de 1\% (vide Tabela 2). Portanto, as três séries são integradas de primeira ordem, isto é, $\mathrm{I}(\mathrm{l})$.

TABELA 2 - TESTES DE RAIZ UNITÁRIA - ADF

\begin{tabular}{lcccc}
\hline Séries & Def. & Teste & Valor crítico $1 \%$ & Valor crítico 5\% \\
\hline DIVPUB & 1 & 0,4902 & $-2,6081$ & $-1,9471$ \\
$\Delta$ DIVPUB & 0 & $-3,9584$ & $-2,6081$ & $-1,9471$ \\
NFSPJR & 1 & 1,2994 & $-2,6081$ & $-1,9471$ \\
$\Delta$ NFSPJR & 0 & $-4,3375$ & $-2,6081$ & $-1,9471$ \\
NFSPP & 2 & $-3,6457$ & $-2,6090$ & $-1,9473$ \\
Câmbio & 9 & 6,2640 & $-2,6168$ & $-1,9486$ \\
$\Delta$ Câmbio & 9 & $-5,0655$ & $-4,1896$ & $-3,5189$ \\
INF & 13 & $-2,5916$ & $-2,6227$ & $-1,9495$ \\
\hline
\end{tabular}

Nota: Teste ampliado de Dickey-Fuller (ADF) - o número de defasagens utilizado para cada série foi definido de acordo com o critério de Schwarz (SC). Para a série Câmbio foi usado constante e tendência. Para as demais séries não foi utilizado constante ou tendência.

Para a definição da ordem do VAR foram utilizados os critérios de Schwarz e Hannan-Quinn. ${ }^{6}$ Observa-se que ambos os critérios indicam que o modelo adequado corresponde àquele com apenas uma defasagem e sem constante, por apresentar os menores valores para SC e HQ (vide Tabela 3). A curta defasagem do VAR é consistente com o fato de se estar utilizando séries de freqüência mensal.

$6 S C=-2(l / T)+k \log (T) / T$ e $H Q=-2(l / T)+2 k \log (\log (T)) / T$; considera uma regressão com $\mathrm{k}$ parâmetros estimados usando T observações. $l$ é o valor do $\log$ da função probabilidade com $k$ parâmetros estimados. 
TABELA 3 - CRITÉRIO DE SC E HQ PARA ORDEM DO VAR

\begin{tabular}{cccc}
\hline Defasagens & Constante & $\mathrm{SC}$ & $\mathrm{HQ}$ \\
\hline 0 & com constante & 8,994421 & 8,874618 \\
1 & com constante & $-1,687706^{*}$ & $-2,406522^{*}$ \\
2 & com constante & $-0,759871$ & $-2,077701$ \\
3 & com constante & 0,327622 & $-1,589221$ \\
4 & com constante & 0,246093 & $-2,269763$ \\
\hline 1 & sem constante & $-1,622529^{*}$ & $-2,221542^{*}$ \\
2 & sem constante & $-0,774605$ & $-1,972632$ \\
3 & sem constante & 0,301795 & $-1,495245$ \\
4 & sem constante & 0,533129 & $-1,862925$ \\
\hline
\end{tabular}

Nota: ${ }^{*}$ denota a ordem selecionada pelo critério. SC: critério de Schwarz. HQ: critério de Hannan-Quinn.

Assumindo-se que os erros são ortogonalizados pela decomposição de Cholesky para a estimação do VAR, isto implica que o ordenamento das variáveis é de crucial importância para a análise da função impulso-resposta. A ordenação que se mostra razoável para análise é dada por: Câmbio, INF, NFSPJR, NFSPP, DIVPUB. A explicação para esta ordem das variáveis pode ser compreendida da seguinte forma. Durante o período sob análise cerca de $10 \%$ da dívida pública esteve indexada ao câmbio. Ademais, o câmbio representou a principal variável de política econômica no período, sendo capaz de disciplinar o comportamento da inflação. A combinação do câmbio e da inflação tem como resultado um aumento (ou redução) da dívida pública por meio do pagamento de juros reais, que, por sua vez, implica uma maior (ou menor) necessidade de geração de superávits primários. Logo, há uma interconexão entre as variáveis que causam impacto sobre a dívida pública. Um outro motivo para esta ordenação das variáveis é sua compatibilidade com o resultado obtido da aplicação do teste de precedência temporal de Granger (vide Tabela 4). 
TABELA 4 - TESTE DE PRECEDÊNCIA TEMPORAL DE GRANGER

\begin{tabular}{lccc}
\hline VAR(1) & & & \\
\hline Hipótese nula: & Obs & Estatística-F & Probabilidade \\
\hline NFSPJR não Granger causa DIVPUB & 52 & 0,91232 & 0,34419 \\
DIVPUB não Granger causa NFSPJR & & 10,9356 & 0,00177 \\
\hline NFSPP não Granger causa DIVPUB & 52 & 9,01373 & 0,00421 \\
DIVPUB não Granger causa NFSPP & & 6,51841 & 0,01384 \\
\hline CAMBIO não Granger causa DIVPUB & 52 & 8,09843 & 0,00645 \\
DIVPUB não Granger causa CAMBIO & & 0,41568 & 0,52211 \\
\hline INF não Granger causa DIVPUB & 52 & 14,6989 & 0,00036 \\
DIVPUB não Granger causa INF & & 0,16475 & 0,68659 \\
\hline NFSPP não Granger causa NFSPJR & 52 & 0,00311 & 0,95578 \\
NFSPJR não Granger causa NFSPP & & 0,14550 & 0,70452 \\
\hline CAMBIO não Granger causa NFSPJR & 52 & 3,38511 & 0,07185 \\
NFSPJR não Granger causa CAMBIO & & 0,44743 & 0,50670 \\
\hline INF não Granger causa NFSPJR & 52 & 1,38150 & 0,24553 \\
NFSPJR não Granger causa INF & & 0,01704 & 0,89669 \\
\hline CAMBIO não Granger causa NFSPP & 52 & 0,75636 & 0,38871 \\
NFSPP não Granger causa CAMBIO & & 2,77409 & 0,10218 \\
\hline INF não Granger causa NFSPP & 52 & 3,03712 & 0,08765 \\
NFSPP não Granger causa INF & & 9,65326 & 0,00314 \\
\hline INF não Granger causa CAMBIO & 52 & 1,03469 & 0,31406 \\
CAMBIO não Granger causa INF & & 11,3619 & 0,00147 \\
\hline & & & \\
\hline
\end{tabular}

Em razão da dificuldade de interpretar os coeficientes estimados para o modelo VAR é usual que os resultados sejam sumariados por meio da decomposição da variância e por intermédio da análise de função impulso-resposta parcial. Devido ao fato de os dados utilizados na amostra serem mensais, a Tabela 5 mostra a explicação da variância das séries sob análise para observação de um choque depois de transcorridos 12 meses. O mesmo período posterior ao choque é assumido quando é feita a análise impulso-resposta para o VAR. 
De acordo com a Tabela 5 verifica-se que a importância relativa das diversas variáveis em análise na explicação da variância da taxa de câmbio não é significativa - cerca de $93 \%$ da variância é explicada pela própria variável. Quanto ao impacto originário de um choque externo sobre os valores passados da própria taxa de câmbio (primeiro gráfico situado na linha supracitada), o resultado indica que o padrão de regularidade não se altera durante os 12 meses. Ademais, a análise impulso-resposta (primeira linha da Figura 2) permite observar que os impactos oriundos da INF, NFSPJR, NFSPP, e DIVPUB se aproximam de zero, denotando que os mesmos são estatisticamente pouco expressivos.

TABELA 5 - DECOMPOSIÇÃA DA VARIÂNCIA APÓS 12 MESES

\begin{tabular}{llcccc}
\hline & Câmbio & INF & NFSPJR & NFSPP & DIVPUB \\
\hline Câmbio & 93,07873 & 0,443156 & 5,106602 & 1,156894 & 0,214618 \\
INF & 1,241957 & 76,05016 & 0,285719 & 7,042716 & 15,37945 \\
NFSPJR & 0,163126 & 28,90179 & 54,34338 & 2,699899 & 13,89180 \\
NFSPP & 6,324738 & 7,188114 & 6,651348 & 21,82436 & 58,01144 \\
DIVPUB & 7,652851 & 23,38594 & 5,698465 & 4,986297 & 58,27645 \\
\hline
\end{tabular}

Nota: Ordem das séries: Câmbio, INF, NFSPJR, NFSPP, e DIVPUB.

Quanto aos resultados relativos à taxa de inflação, observa-se que a importância da própria INF na explicação de sua variância é muito significativa (76\%). Todavia, o segundo gráfico da segunda linha da Figura 2 revela que a regularidade apresenta um declínio dos impactos tendendo a se anular a partir do sétimo mês. A importância relativa da dívida pública na explicação da inflação é significativa (15\%). Além disso, o último gráfico da linha supracitada mostra que os efeitos de um choque da DIVPUB sobre a INF tende a se afastar de zero, indicando significância estatística. Este resultado ratifica o argumento defendido por alguns autores, como Calvo (1988), de que a tendência do banco central inflacionar a economia é uma função da dívida pública, e que, portanto, uma redução de seu estoque seria capaz de reduzir a pressão sobre o banco central im- 
plicando maior credibilidade à condução da política monetária. ${ }^{7}$ Por outro lado, embora em menor escala, o efeito de um choque proveniente da NFSPP sobre a variância da INF também não é desprezível (7\%). Não obstante, o penúltimo gráfico localizado na linha sobredita evidencia que os efeitos de choques externos, transmitidos pela variável NFSPP sobre a INF, são estatisticamente pouco expressivos. O mesmo pode ser dito (não há significância estatística) para os possíveis efeitos transmitidos pelo câmbio e NFSPJR para a variância da INF.

Em relação à NFSPJR, observa-se que a importância relativa da variável na explicação de sua variância é significativa (54\%), e que o terceiro gráfico localizado na terceira linha da Figura 2 exibe um padrão de regularidade que praticamente não se altera nos 12 meses. Também é observado, por meio da Tabela 5 e da Figura 2, que a taxa de câmbio e NFSPP não desempenham papel relevante na explicação da NFSPJR. Por outro lado, a INF e a DIVPUB merecem maior atenção. A importância relativa da INF na variância da NFPJR é expressiva (29\%). Ademais, o segundo gráfico situado na segunda linha denota significância estatística, uma vez que os efeitos de um choque da INF sobre a DIVPUB tendem a se afastar de zero. A explicação para esse resultado é que uma inflação mais elevada pode estar associada a uma monetização da dívida e, portanto, devido a um menor estoque da dívida haveria uma menor despesa com o pagamento de juros. Outrossim, a DIVPUB possui papel de destaque na explicação da variância da NFSPJR (14\%). O último gráfico localizado na linha já referida indica, conforme esperado, que um aumento no endividamento público tem como resultado um incremento na despesa do governo com o pagamento de juros.

7 Durante os anos 80 , diversos trabalhos procuraram analisar o efeito do déficit e da dívida sobre a credibilidade da política monetária tendo como base a estrutura teórica desenvolvida por KYDLAND \& PRESCOTT (1977). Para o leitor interessado na literatura, ver LUCAS \& STOKEY (1983), PERSSON, PERSSON \& SVENSSON (1987), CALVO (1988) e BOHN (1988). 
FIGURA 2 - FUNÇÃO IMPULSO-RESPOSTA PARA O VAR
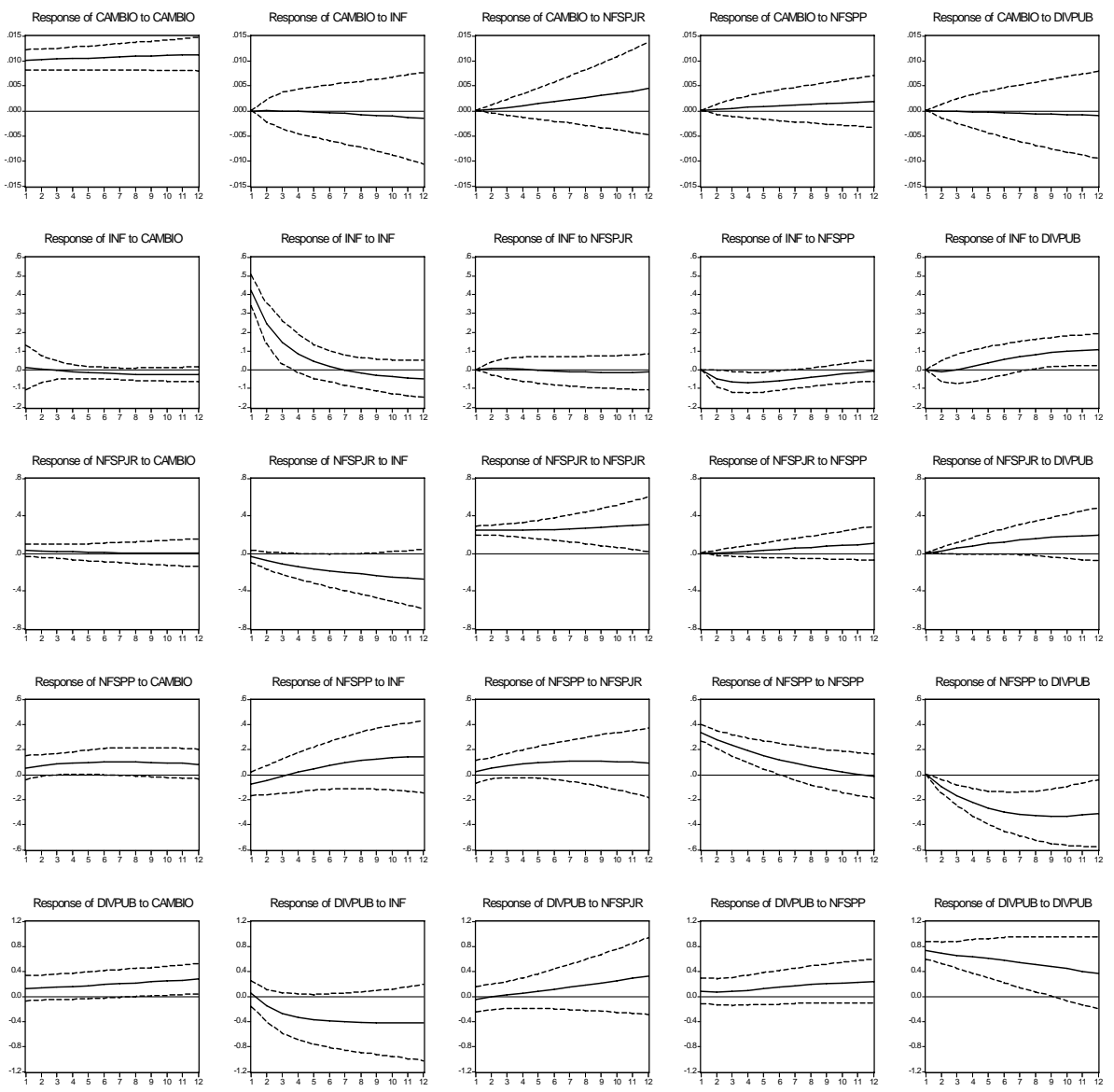

Quanto à NFSPP, observa-se que a importância relativa da própria variável na explicação de sua variância é menor do que nos casos anteriores $(22 \%)$. A resposta da NFSPP ao impacto originário de um choque externo sobre os seus valores passados (penúltimo gráfico localizado na quarta linha da Figura 2) mostra um declínio dos impactos tendendo a se anular no décimo segundo mês. A Tabela 5 mostra que a importância do câmbio, INF, e NFSPJR na explicação da variância da NFSPP são semelhantes (oscilando entre $6 \%$ e $7 \%$ ). O mesmo pode ser dito sobre os efeitos de choques externos transmitidos por essas variáveis. Um impacto positivo nessas variáveis tende a provocar uma elevação na NFSPP que não é eliminada ao longo do tempo (vide primeiro, segundo e terceiro gráficos situados na linha sobredita). A variável de destaque para a explicação da NFSPP é a DIVPUB. A 
importância relativa da DIVPUB na explicação da variância da NFSPP é muito significativa (58\%). A análise impulso-resposta ratifica a importância da DIVPUB para a NFSPP, demonstrando significância estatística. Conforme pode ser observado pelo último gráfico localizado na linha supradita, um choque positivo transmitido pela DIVPUB tende a reduzir a NFSPP. Em outras palavras, o aumento do endividamento público tende a implicar a necessidade da geração de superávits primários para estabilizar a razão dívida/PIB.

Para a análise da DIVPUB observa-se que a importância relativa da própria variável para a compreensão de sua variância é significativa (58\%). Ademais, o último gráfico localizado na quinta linha da Figura 2 denota que os impactos decorrentes de choques externos da própria variável indicam um declínio dos impactos, sem, contudo, anular-se. Este resultado sugere que a principal variável para a explicação do endividamento público é o próprio estoque da dívida. A INF também possui relevância para a explicação da variância da DIVPUB (23\%). O segundo gráfico localizado na linha já mencionada mostra que um choque positivo transmitido pela INF tende a reduzir a DIVPUB. As variáveis Câmbio, NFSPJR, e NFSPP possuem performance similares. O efeito dessas variáveis na explicação da variância da DIVPUB situou-se entre $5 \%$ e $8 \%$. Ademais, o primeiro, terceiro e quarto gráficos localizados na última linha da Figura 2 mostram que um choque positivo transmitido por essas variáveis tende a elevar a DIVPUB. ${ }^{8}$

\section{RESULTADOS EMPÍRICOS: JANEIRO DE 1999 - ABRIL DE 2003}

Seguindo a mesma metodologia utilizada na seção anterior é feito um modelo VAR contendo as variáveis listadas na seção 1 . Antes de fazer o modelo é preciso verificar se as séries são estacionárias em nível ou em suas diferenças. Conforme pode ser observado por meio da Figura 3, com exceção das séries DIVPUB e Câmbio, as demais séries revelam que os coeficientes de autocorrelação simples não declinam de forma lenta e gradual à medida que o número de defasagens aumenta. Portanto, há indício de que essas séries são estacionárias em nível.

8 Deve-se ressaltar que na maioria dos casos a significância estatística náo se mostrou robusta devido ao fato de os valores situarem-se próximos a zero durante os 12 meses. 


\section{FIGURA 3 - EVOLUÇÃO E CORRELOGRAMA DAS SÉRIES}
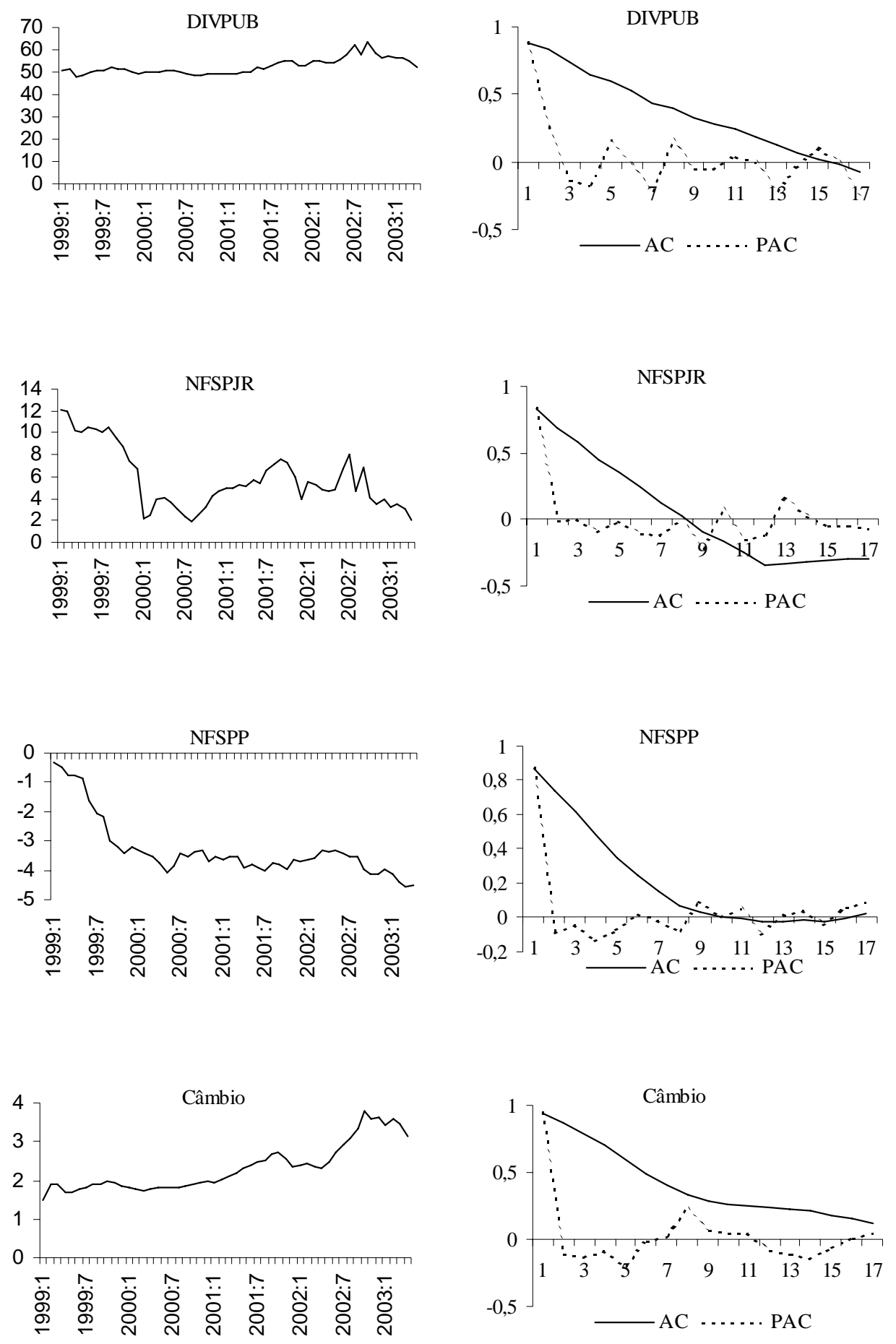

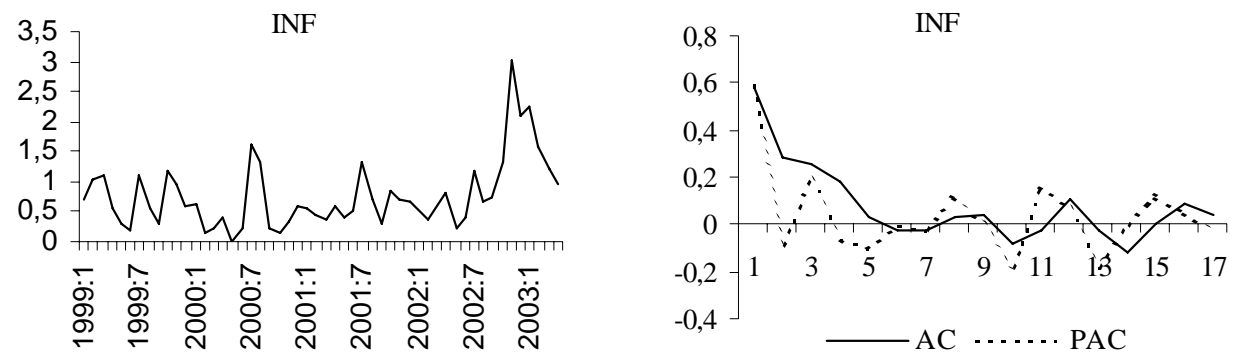

A realização do teste ADF (vide Tabela 6), em conformidade com que se esperava por meio da visualização dos correlogramas presentes na Figura 3, atestou que as séries NFSPJR, NFSPP e INF são estacionárias em nível, enquanto que as séries DIVPUB e Câmbio são integradas de primeira ordem.

TABELA 6 - TESTES DE RAIZ UNITÁRIA - ADF

\begin{tabular}{lcccc}
\hline Séries & Def. & Teste & Valor crítico $1 \%$ & Valor crítico $5 \%$ \\
\hline DIVPUB & 0 & $-0,0021$ & $-2,6081$ & $-1,9471$ \\
$\Delta$ DIVPUB & 0 & $-9,2988$ & $-2,6090$ & $-1,9473$ \\
NFSPJR & 0 & $-1,9947$ & $-2,6081$ & $-1,9471$ \\
NFSPP & 0 & $-3,3132$ & $-3,5625$ & $-2,9190$ \\
Câmbio & 1 & 0,5991 & $-2,6090$ & $-1,9473$ \\
$\Delta$ Câmbio & 0 & $-5,6508$ & $-2,6090$ & $-1,9473$ \\
INF & 0 & $-3,5661$ & $-3,5625$ & $-2,9190$
\end{tabular}

Nota: Teste ampliado de Dickey-Fuller (ADF) - o número de defasagens utilizado para cada série foi definido de acordo com o critério de Schwarz (SC). Para as séries NFSPP e INF foi usado constante. Para as demais séries não foi utilizado constante ou tendência.

Fazendo-se uso dos critérios de Schwarz e Hannan-Quinn para a definição da ordem ótima do VAR, verificou-se que o modelo adequado refere-se àquele com uma defasagem e uso de constante (vide Tabela 7). 
TABELA 7 - CRITÉRIO DE SC E HQ PARA ORDEM DO VAR

\begin{tabular}{cccc}
\hline Defasagens & Constante & $\mathrm{SC}$ & $\mathrm{HQ}$ \\
\hline 0 & com constante & 12,85574 & 12,73448 \\
1 & com constante & $7,017672^{*}$ & $6,290127^{*}$ \\
2 & com constante & 7,918988 & 6,585156 \\
3 & com constante & 9,157670 & 7,217550 \\
4 & com constante & 9,707989 & 7,161583 \\
\hline 1 & sem constante & $7,350651^{*}$ & 6,744364 \\
2 & sem constante & 7,860242 & $6,647668^{*}$ \\
3 & sem constante & 9,203563 & 7,384702 \\
4 & sem constante & 9,709461 & 7,284312 \\
\hline
\end{tabular}

Nota: * denota a ordem selecionada pelo critério. SC: critério de Schwarz. HQ: critério de Hannan-Quinn.

Devido à mudança no regime cambial ocorrida em janeiro de 1999 a ordenação das variáveis para a estimação do VAR não é a mesma que a do período anterior. Conforme pode se observado por meio do teste de precedência temporal de Granger (vide Tabela 8), o ordenamento que se mostra razoável para análise é dado por: DIVPUB, Câmbio, NFSPP, INF, NFSPJR. A justificativa para esse resultado é que o aumento do estoque da dívida pública no período tornou-se uma variável de grande importância na determinação das outras variáveis sob análise. $\mathrm{O}$ aumento do endividamento público provoca uma flutuação cambial que, por sua vez, implica a necessidade de um aumento no superávit primário para conter a trajetória da inflação. O resultado da combinação dos efeitos provenientes dessas variáveis é uma elevação (ou queda) na despesa financeira com o pagamento de juros do setor público. 
TABELA 8 - TESTE DE PRECEDÊNCIA TEMPORAL DE GRANGER

\begin{tabular}{lccc}
\hline VAR(1) & Obs & Estatística-F & Probabilidade \\
\hline Hipótese nula: & 51 & 0,39893 & 0,53064 \\
\hline NFSPJR não Granger causa DIVPUB & & 2,45813 & 0,12349 \\
DIVPUB não Granger causa NFSPJR & 51 & 0,00353 & 0,95289 \\
\hline NFSPP não Granger causa DIVPUB & & 1,83892 & 0,18142 \\
DIVPUB não Granger causa NFSPP & 51 & 0,00075 & 0,97828 \\
\hline CAMBIO não Granger causa DIVPUB & & 28,9225 & $2,2 E-06$ \\
DIVPUB não Granger causa CAMBIO & & 0,66832 & 0,41768 \\
\hline INF não Granger causa DIVPUB & 51 & 6,57531 & 0,01353 \\
DIVPUB não Granger causa INF & & 5,86448 & 0,01928 \\
\hline NFSPP não Granger causa NFSPJR & 51 & 0,30028 & 0,58625 \\
NFSPJR não Granger causa NFSPP & & 1,63749 & 0,20682 \\
\hline CAMBIO não Granger causa NFSPJR & 51 & 1,34362 & 0,25213 \\
NFSPJR não Granger causa CAMBIO & & 1,45033 & 0,23438 \\
\hline INF não Granger causa NFSPJR & 51 & 0,02581 & 0,87305 \\
NFSPJR não Granger causa INF & & 1,22694 & 0,27352 \\
\hline CAMBIO não Granger causa NFSPP & 51 & 0,45066 & 0,50524 \\
NFSPP não Granger causa CAMBIO & & 0,20550 & 0,65236 \\
\hline INF não Granger causa NFSPP & 51 & 0,61440 & 0,43699 \\
NFSPP não Granger causa INF & & 1,26698 & 0,26593 \\
\hline INF não Granger causa CAMBIO & 51 & 11,9718 & 0,00114 \\
CAMBIO não Granger causa INF & & & \\
\hline
\end{tabular}

A análise do VAR está sumariada pelos resultados apresentados na decomposição da variância das variáveis sob análise (vide Tabela 9) e de suas funções de impulsos-respostas depois de transcorridos 12 meses (vide Figura 4).

TABELA 9 - DECOMPOSIÇÃO DA VARIÂNCIA APÓS 12 MESES

\begin{tabular}{lccccc}
\hline & DIVPUB & Câmbio & NFSPP & INF & NFSPJR \\
\hline DIVPUB & 89,83909 & 1,419102 & 0,979435 & 1,609843 & 6,152528 \\
Câmbio & 83,76400 & 8,112738 & 1,047469 & 0,596956 & 6,478836 \\
NFSPP & 16,11679 & 2,962665 & 74,74484 & 4,709141 & 1,466563 \\
INF & 31,81062 & 5,809336 & 2,468657 & 58,28349 & 1,627895 \\
NFSPJR & 35,35088 & 2,996618 & 16,11329 & 4,538503 & 41,00071 \\
\hline
\end{tabular}

Nota: Ordem das séries: DIVPUB, Câmbio, NFSPP, INF, e NFSPJR. 
De acordo com a Tabela 9, constata-se que a importância relativa das diversas variáveis em análise na explicação da variância da DIVPUB não é significativa, uma vez que aproximadamente $90 \%$ de sua variância é explicada por si mesma. Em relação ao efeito oriundo de um choque externo sobre os valores passados da própria DIVPUB (primeiro gráfico situado na primeira linha da Figura 4), observa-se que a regularidade indica um declínio dos impactos, sem, contudo, anular-se até o décimo segundo mês. Quanto às demais variáveis, observa-se que os efeitos de choques externos transmitidos estão próximos de zero, o que denota falta de significância estatística. Este resultado sugere que o principal responsável pela trajetória da dívida pública é o seu próprio estoque.

Ao contrário do período anterior, em que a taxa de câmbio era a principal responsável pela explicação de sua dinâmica, para o período em consideração a DIVPUB representa a variável mais importante na análise de sua variância $(84 \%)$, ao passo que a taxa de câmbio ficou reduzida a apenas $8 \%$. Os dois primeiros gráficos localizados na segunda linha da Figura 4 mostram o impacto de um choque externo transmitido pelas variáveis DIVPUB e Câmbio respectivamente sobre a taxa de câmbio. A importância da DIVPUB na explicação do câmbio é muito significativa, uma vez que os efeitos de um choque, ao longo do tempo, encontram-se bem afastados de zero. Por outro lado, a importância da taxa de câmbio na transmissão de um choque sobre si mesma não se mostrou significativo, tendendo a desaparecer o efeito do choque a partir do sexto mês. Conforme pode ser observado por meio dos demais gráficos na linha supracitada, as outras variáveis mostram-se desimportantes para a análise da função impulso-resposta devido à falta de significância estatística.

A importância relativa da NFSPP na explicação de sua variância é significativa (75\%). A Tabela 9 mostra que além da própria variável, apenas a DIVPUB também é relevante para análise da variância da NFSPP, uma vez que as variáveis câmbio, INF, NFSPJR juntas explicam apenas cerca de $9 \%$ de sua variância. A análise impulso-resposta revela que os impactos decorrentes de choques externos da própria variável (vide terceiro gráfico localizado na terceira linha da Figura 4) tendem a se reduzir à medida que o tempo passa. Além disso, observa-se que os efeitos de um choque positivo transmi- 
tido pela DIVPUB não são eliminados ao longo do tempo (vide primeiro gráfico situado na linha sobredita). Esse resultado converge com aquele encontrado para o período anterior, sugerindo que o aumento no estoque da dívida pública leva à geração de superávits primários para estabilizar a razão dívida/PIB. As variáveis restantes não mostraram relevância estatística para análise da transmissão de choques externos para a NFSPP.

\section{FIGURA 4 - FUNÇÃO IMPULSO-RESPOSTA PARA O VAR}
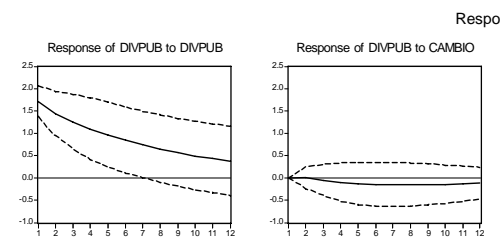

Response to Cholesky One S.D. Innovations \pm 2 S.E.
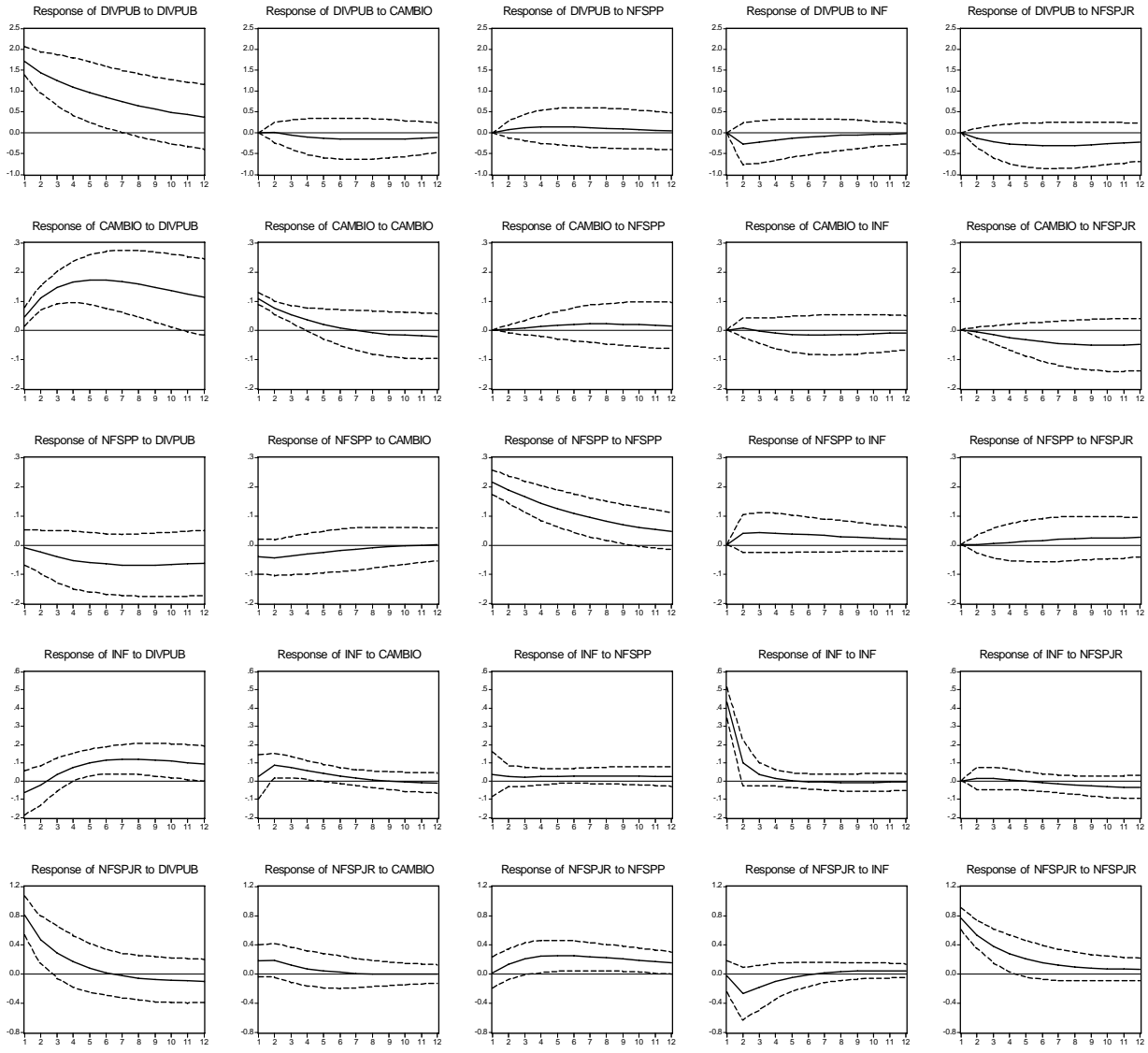

Quanto aos resultados referentes à taxa de inflação, verifica-se que a importância a própria INF na explicação de sua variância é significativa $(58 \%)$. Não obstante, o quarto gráfico localizado na quarta linha da Figura 4 mostra que os efeitos decorrentes da transmissão de um choque pela própria va- 
riável é efêmero, sofrendo forte queda depois do primeiro mês. Este resultado sugere que a presença de um componente inercial na explicação da trajetória da inflação é desprezível. O ponto que merece destaque na análise da inflação é a importância relativa da dívida pública na explicação de sua variância (32\%). Ademais, o primeiro gráfico localizado na linha supracitada indica que o efeito de um choque positivo da DIVPUB tende a elevar a INF de forma duradoura. Mais uma vez, este resultado mostra-se compatível com o argumento de que uma elevação no estoque da dívida pública pode acarretar uma monetização da dívida, que culmina com o aumento da inflação. A importância relativa da taxa de câmbio na análise da variância da INF não é muito expressiva (6\%) e o impacto de uma elevação da INF devido a um choque externo transmitido pelo câmbio tende a se anular a partir do oitavo mês (vide segundo gráfico localizado na linha sobredita). Por último, as variáveis NFSPP e NFSPJR não se mostraram relevantes para a análise da dinâmica da INF.

Para a análise da NFSPJR, observa-se que a importância relativa da variável na explicação de sua variância é significativa (41\%). Entretanto, conforme pode ser visualizado pelo último gráfico localizado na última linha da Figura 4, o impacto de um choque transmitido pela própria variável tende a reduzir-se, tornando-se insignificante ao final de 12 meses. Ainda que a análise impulso-resposta revele que um choque positivo transmitido por meio da taxa de câmbio leve a um aumento da NFSPJR (vide segundo gráfico da linha já mencionada) e que um aumento da inflação acarrete uma redução na variável sob análise (vide terceiro gráfico da mesma linha), os efeitos têm curta duração e não são estatisticamente expressivos. Em contrapartida, as variáveis DIVPUB e NFSPP possuem importância relativa na variância da NFSPJR, explicando cerca de $35 \%$ e $16 \%$, respectivamente. Conforme pode ser observado por meio do primeiro gráfico localizado na quinta linha da Figura 4, um choque positivo transmitido pela DIVPUB eleva a NFSPJR, mas o efeito tende a declinar e desaparecer por completo a partir do sexto mês. Por outro lado, o terceiro gráfico da mesma linha mostra que (ainda que estatisticamente pouco expressivo) um aumento (redução) da NFSPP tende a elevar (diminuir) a NFSPJR, perdurando ao longo dos 12 meses. Em outras palavras, um aumento no superávit (déficit) primário ten- 
de a reduzir (aumentar) as despesas do setor público com o pagamento de juros.

\section{CONCLUSÃO}

A análise referente ao período agosto de 1994 a dezembro de 1998 revelou que a trajetória da dívida pública foi explicada, em grande medida, pelo seu próprio estoque. A queda da taxa de inflação observada nesse intervalo de tempo não foi suficiente para promover uma redução nas despesas com o pagamento de juros reais do setor público. A justificativa para esse fenômeno se deve a dois pontos: (i) a vulnerabilidade da economia com o regime de câmbio fixo, que culminou com uma elevação da taxa de juros reais no final desse período; e (ii) ao estupendo aumento do uso da SELIC como principal indexador da dívida, que saltou de 22,07\% em agosto de 1994 para 70,18\% em dezembro de 1998. Ademais, observa-se que a combinação da desvalorização gradual da moeda com o aumento das NFSPJR, devido às crises asiática e russa, e ainda a menor austeridade com o resultado primário a partir do início de 1996 contribuíram para uma elevação sustentada no endividamento público.

O motivo para a mudança no padrão da dívida pública com a alteração do regime cambial ocorrida em janeiro de 1999 se deve ao fato de que cerca de $30 \%$ da dívida pública estava indexada ao câmbio. Não obstante, conforme pôde ser observado por meio dos resultados encontrados na quarta seção, verificou-se que a dinâmica da dívida no período compreendido entre janeiro de 1999 e abril de 2003 tem o seu estoque como a principal variável explicativa.

Os resultados encontrados para ambos os subperíodos analisados indicam que a estabilidade de preços obtida não foi o bastante para fomentar reduções no estoque da dívida pública. Além disso, deve-se ressaltar que os possíveis efeitos do superávit primário observado no período posterior a janeiro de 1999 sobre a dívida pública foram neutralizados por meio de sucessivas desvalorizações da moeda e da manutenção da SELIC em um patamar ele- 
vado. ${ }^{9}$ Portanto, o problema para o endividamento público brasileiro não deve ser creditado à autoridade monetária devido aos custos fiscais indesejados que uma política monetária restritiva impõe. Uma forma de atenuar o problema é via alteração da estrutura de indexação da dívida, reduzindo-se a proporção de títulos atrelados à SELIC e ao câmbio e aumentando a quantidade de títulos indexados à inflação. Deste modo, elevações de juros arrefecendo pressões inflacionárias levariam também a reduções na razão dívida/ PIB, aumentando a credibilidade da política antiinflacionária. ${ }^{10}$

\section{REFERÊNCIAS BIBLIOGRÁFICAS}

BACK, J. L.; MUSGRAVE, R. A. A stable purchasing power bond. American Economic Review, 31, p. 823-825, 1941.

BOHN, H. Why do we have nominal government debt? Journal of Monetary Economics, 21, p. 127-140, 1988.

CALVO, G. Servicing the public debt: the role of expectations. American Economic Review, 78, p. 647-661, 1988.

CALVO, G.; GUIDOTTI. Indexation and maturity of government bonds: an exploratory model. In: DORNBUSCH, R.; DRAGHI, M. (eds.), Public debt management: theory and history. Cambridge: Cambridge University Press, 1990, p. 52-93.

de MENDONÇA, H. F. Regimes monetários e a busca da estabilidade de preços: o uso de metas para a taxa de câmbio, agregados monetários e inflação. Revista de Economia Politica, v. 22, n. 1 (85), p. 34-52, jan-mar 2002.

. Metas de inflação: uma análise preliminar para o caso brasileiro. Economia Aplicada, FIPE/FEA-USP, São Paulo, v. 5, n. 1, p. 129158, jan-mar 2001.

DICKEY, D. A.; FULLER, W. A. Distribution of the estimators for autoregressive time series with a unit root. Joumal of the American Statistical Association, 74, p. 427-431, 1979.

DOLADO, J.; JENKINSON, T.; SOSVILLA-ROVERA, S. Cointegration and unit roots. Journal of Economic Surveys, 4, p. 249-273, 1990.

9 Em abril de 2003 cerca de $68 \%$ da dívida pública estava atrelada à SELIC e $15 \%$ ao câmbio.

10 Este argumento foi construído originalmente por BACK \& MUSGRAVE (1941), sendo desenvolvido no período mais recente por LUCAS \& STOKEY (1983), BOHN (1988), CALVO (1988), e CALVO \& GUIDOTTI (1990). 
GOLDBERGER, A. S. A course in econometrics. Cambridge, Massachusetts: Harvard University Press, 1991.

GRANGER, C. W. J. Investigating causal relations by econometric models and cross-spectral methods. Econometrica, 37, p. 424-438, 1969.

KING, M. Commentary: monetary policy implications of greater fiscal discipline. In: Budget deficits and debt: issues and options. Federal Reserve Bank of Kansas City. August-September, 1995, p. 171-183.

KYDLAND, F. E.; PRESCOTT, E. C. Rules rather than discretion: the inconsistency of optimal plans. Joumal of Political Economic, v. 85, n. 3, p. 473-492, 1977.

LUCAS, R.; STOCKEY, N. Optimal fiscal and monetary policy in an economy without capital. Journal of Monetary Economics, 12, p. 5593, 1983.

NETO, A. D. Sobre as metas inflacionárias. Economia Aplicada, FIPE/ FEA-USP, São Paulo, v. 3, n. 3, p. 357-382, jul-set 1999.

PERSSON, M.; PERSSON, T.; SVENSSON, L. Time consistency of monetary and fiscal policy. Econometrica, 55, p. 1419-1432, 1987.

TAYLOR, J. B. Monetary policy implications of greater fiscal discipline. In: Budget deficits and debt: issues and options. Federal Reserve Bank of Kansas City. August-September, 1995, p. 151-170.

Agradeço os profícuos comentários realizados por dois pareceristas anônimos desta Revista. Possíveis erros e omissões são de exclusiva responsabilidade do autor.

(Recebido em dezembro de 2002. Aceito para publicação em março de2004). 